\title{
Pressing Issues in COVID-19: Probable Cause to Seize SARS- CoV-2 for Its Preferential Involvement of Posterior Circulation Manifesting as Severe Posterior Reversible Encephalopathy Syndrome and Posterior Strokes
}

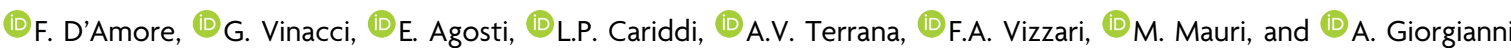

\begin{abstract}
SUMMARY: Since December 2019, a novel Severe Acute Respiratory Syndrome coronavirus 2 from China has rapidly spread worldwide. Although respiratory involvement is the mainstay of coronavirus disease 2019 (COVID-19), systemic involvement has recently drawn more attention. In particular, a number of recent articles have shed light on the nervous system as one of the possible targets. At our institution, we observed 15 patients with acute brain vascular manifestations; most interesting, we had a higher prevalence of the posterior circulation acute impairment. In our series, 7 patients had acute posterior cerebral injury: 1, hemorrhagic posterior reversible encephalopathy syndrome; 5, posterior circulation ischemic stroke; and 1, parieto-occipital hemorrhagic stroke. On the basis of our evidence and previous basic science reports, we believe a common etiopathogenetic thread may connect ischemic/hemorrhagic events of the posterior circulation and posterior reversible encephalopathy syndrome in the setting of COVID-19.
\end{abstract}

ABBREVIATIONS: COVID-19 = coronavirus disease 2019; PRES = posterior reversible encephalopathy syndrome; SARS-CoV-2 = Severe Acute Respiratory Syndrome coronavirus 2

ast December, the first cases of a novel viral coronavirus disease 2019 (COVID-19) caused by the Severe Acute Respiratory Syndrome coronavirus 2 (SARS-CoV-2) were identified in China. Since then, the virus has spread so quickly worldwide that the World Health Organization declared COVID-19 a pandemic on March 11, 2020. ${ }^{1}$ Italy first faced the largest outbreak besides Asia, with Lombardy outnumbering all other regions in Italy in terms of COVID-19 infections and deaths. As of May 21, >5 million SARS-CoV-2 infections have been confirmed worldwide, with the highest number of cases $(>1.5$ million) and deaths (almost 100,000) registered in the United States. ${ }^{2}$ From the beginning of this medical emergency, our hospital has admitted $>1100$ patients who tested positive for SARS$\mathrm{CoV}-2 .^{3}$ Although it is well-known that SARS-CoV-2 has a

Received May 21, 2020; accepted after revision June 3.

From the Departments of Neuroradiology (F.D., A.V.T., F.A.V., A.G.) and Neurology and Stroke Unit (L.P.C., M.M.), Hospital of Circolo and Macchi Foundation, Varese, Lombardia, Italy; Departments of Radiology (G.V.) and Neurosurgery (E.A.), University of Insubria, Hospital of Circolo and Macchi Foundation, Varese, Lombardia, Italy; and Clinical and Experimental Medical Humanities (L.P.C.), Center of Research in Medical Pharmacology, Univeristy of Insubria, Varese, Italy.

Please address correspondence to Gabriele Vinacci, MD, University of Insubria, Department of Radiology, Hospital of Circolo and Macchi Foundation, Viale Luigi Borri, 57, Varese, 21100, Italy; e-mail: gabriele_vinacci@libero.it

- Indicates open access to non-subscribers at www.ajnr.org

Indicates article with supplemental on-line table.

http://dx.doi.org/10.3174/ajnr.A6679 preferential pulmonary and gastrointestinal tropism, current evidence points to multiorgan involvement. A growing number of studies have reported SARS-CoV-2 involvement of the CNS, showing a wide variety of neurologic symptoms. ${ }^{4}$ According to a Chinese study, the incidence of neurologic symptoms was about $36 \%$ in a cohort of patients with COVID-19. ${ }^{5}$

\section{Case Series}

From February 21 to the submission of this article, we collected patients positive for SARS-CoV-2 presenting with neurologic impairment who underwent CT and CTA and/or MR imaging (On-line Table). Demographic, clinical, and anamnestic data (age, sex, and clinical data) were obtained from clinical records. All imaging examinations were separately reviewed by 3 boardcertified Neuroradiologists (F.D., A.V.T., A.G., with, respectively, 7,6 , and 10 years of experience in neuroimaging).

A total of 27 patients satisfied the inclusion criteria. Among these, 15 ( 7 men, 8 women; mean age, 68 years; range, 21-88 years) had acute imaging findings (On-line Table), of whom, 7 patients had acute posterior circulation ischemic-hemorrhagic events. The remainder showed miscellaneous findings: 1 case with supratentorial posttraumatic SAH, 2 cases with spontaneous acute or chronic convexities subdural hemorrhage, 1 posttraumatic, 2 with spontaneous intraparenchymal supratentorial hemorrhage (with negative findings on CTA), 1 with multicompartmental 


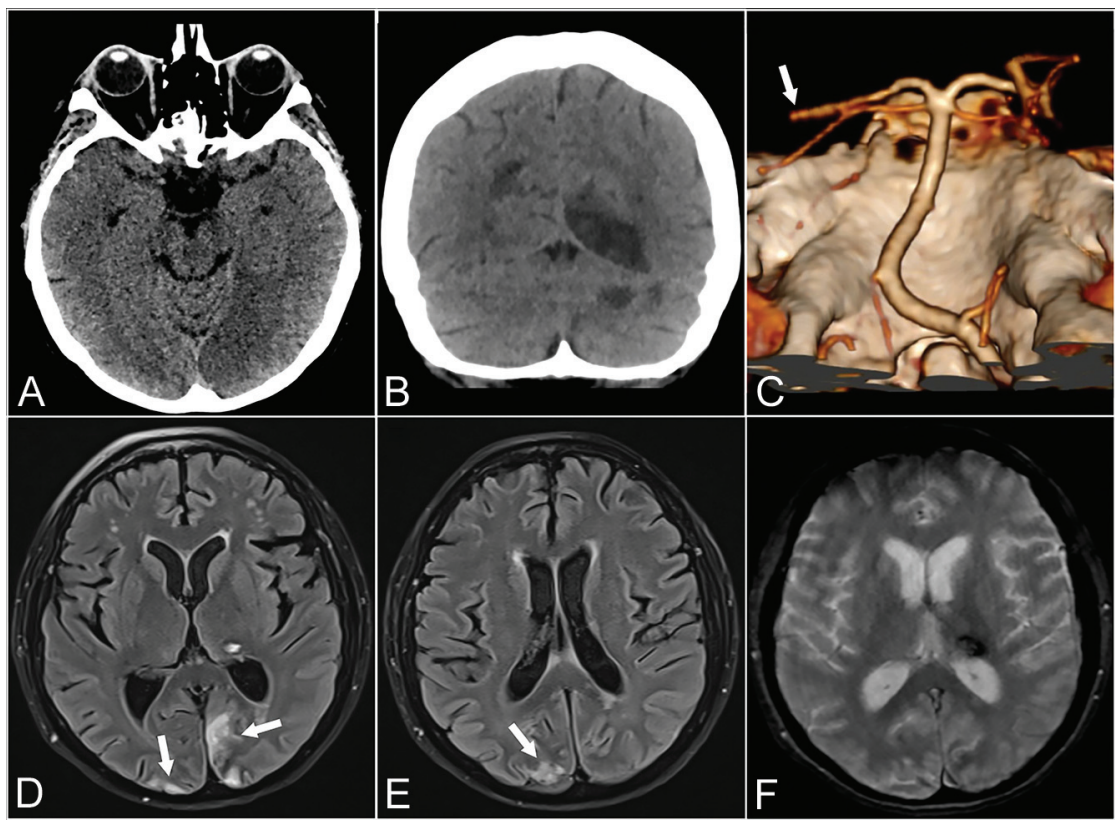

FIG 1. Patient 1. A 57-year-old woman with psychomotor retardation, left gaze deviation, and right superior and inferior limb paresis. Axial CT at baseline shows medial occipital loss of graywhite differentiation consistent with acute ischemia $(A)$. Ten days later, coronal $C T$ shows additional well-defined left cerebellar and right parieto-occipital hypoattenuating areas in keeping with subacute ischemia (B). Left distal posterior cerebral artery occlusion on CTA VR (Volume Rendering) reformats from the same day (white arrow, $C$ ). Axial T2 FLAIR ( $D$ and $E$ ) and axial T2* gradient recalled-echo $(F) 6$ weeks later show focal left thalamic signal drop-out, consistent with hemorrhage. Early chronic ischemic changes are also noted in the parieto-occipital lobes (white arrows, $D$ and $E$ ).

bleeding of unknown etiology, and 1 patient who developed clinical and imaging findings in keeping with encephalitis. CT did not show any acute findings in 12 cases. In all patients with a baseline brain CT scan positive for acute changes, 6 underwent CTA, and MR imaging was available in 4 cases; all had CT follow-up, except those who died.

The subgroup of posterior circulation acute events comprised 7 patients ( 3 men, 4 women; mean age, 72 years, range, $57-88$ years) representing $47 \%$ (7/15) of the total positive cases (On-line Table). In 5 patients, acute ischemic changes were found (Fig 1), of which 2 cases evolved into hemorrhagic transformation. One patient showed right parieto-occipital hemorrhagic stroke at baseline; subsequent CTA ruled out vascular malformations or acute thrombosis. In the other patient, imaging at baseline revealed extensive bilateral subcortical edema with multifocal hemorrhages, predominantly in the occipital lobes. Follow-up imaging showed progressive resorption of edema and hemorrhages, in keeping with posterior reversible encephalopathy syndrome (PRES) (Fig 2).

\section{DISCUSSION}

Our series shows a high prevalence of posterior circulation vascular events, not directly referable to a secondary cause as opposed to the heterogeneous etiology in the remaining cases. We speculate that SARS-CoV-2 may have played a role leading to acute brain injury, with a preferential involvement of the posterior circulation, which may be more susceptible to the SARS-CoV-2 infection effects.

Although SARS-CoV-2 targets primarily the lung parenchyma, earlier evidence in the literature highlighted its neurotrophic and neuroinvasive tendencies. ${ }^{6}$ SARS-CoV-2 invades the CNS through different pathways, from peripheral nerves, especially via the olfactory nerves, through the bloodstream by infecting endothelial cells and altering the $\mathrm{BBB}$, by lymphatic pathways, and, last, by the disruption of the gastrointestinal environment, which may indirectly alter BBB integrity. ${ }^{7}$ SARS-CoV-2 can interact with host cells through the angiotensinconverting enzyme 2 cell membrane receptor expressed in a wide variety of cells such as airway epithelia, lung parenchyma, kidney cells, small intestine cells, as well as neurons and vascular endothelia. ${ }^{6}$ Once it binds to neuronal angiotensin-converting enzyme 2 receptors, it is able to activate a selfreinforcing inflammatory response through a cytokine storm, which ultimately results in irreversible neuronal damage. ${ }^{8}$ Angiotensin-converting enzyme 2 receptors are expressed in cerebral endothelial cells that take part in hormone formation, the sympathoadrenal system, and vascular autoregulation. ${ }^{9}$ Endothelial disruption as a consequence of endotheliitis induced by SARS-CoV-2 can contribute to the pathophysiology of brain damage. ${ }^{6}$ Infective lymphocytic endotheliitis has been proved by postmortem analysis. ${ }^{10}$ The neuroinvasive potential is also supported by clinical experience as reported by several recent studies. For example, a Chinese study ${ }^{5}$ reported various manifestations of CNS involvement in 53 patients with COVID-19 in a sample of 214 patients. In another study, SARS-CoV-2 was found in the CSF in a patient diagnosed with encephalitis, therefore confirming its direct CNS invasion. ${ }^{11}$ Other studies have also highlighted imaging features of COVID19 brain involvement. ${ }^{12-15}$

As recently described, ischemic stroke is a known complication in patients with COVID-19. In our series, we found 5 ischemic strokes of the posterior circulation in line with other studies. Mao et $\mathrm{al}^{5}$ described 4 cases of acute stroke, while others described the onset of acute ischemic stroke in 5 younger patients. ${ }^{15}$ Beyrouti et al $^{12}$ described 6 cases of acute stroke, 4 of which were posterior strokes. Goldberg and Goldberg ${ }^{16}$ recently showed a case of ischemic stroke with occlusion of the MCA and bilateral anterior cerebral arteries.

Ischemic stroke could be related both to the endotheliitis process $^{10}$ and hypercoagulability status, which can evolve to embolism. ${ }^{17}$ Endothelium inflammation may shift vascular equilibrium toward vasoconstriction, leading to ischemia. ${ }^{18} \mathrm{We}$ 

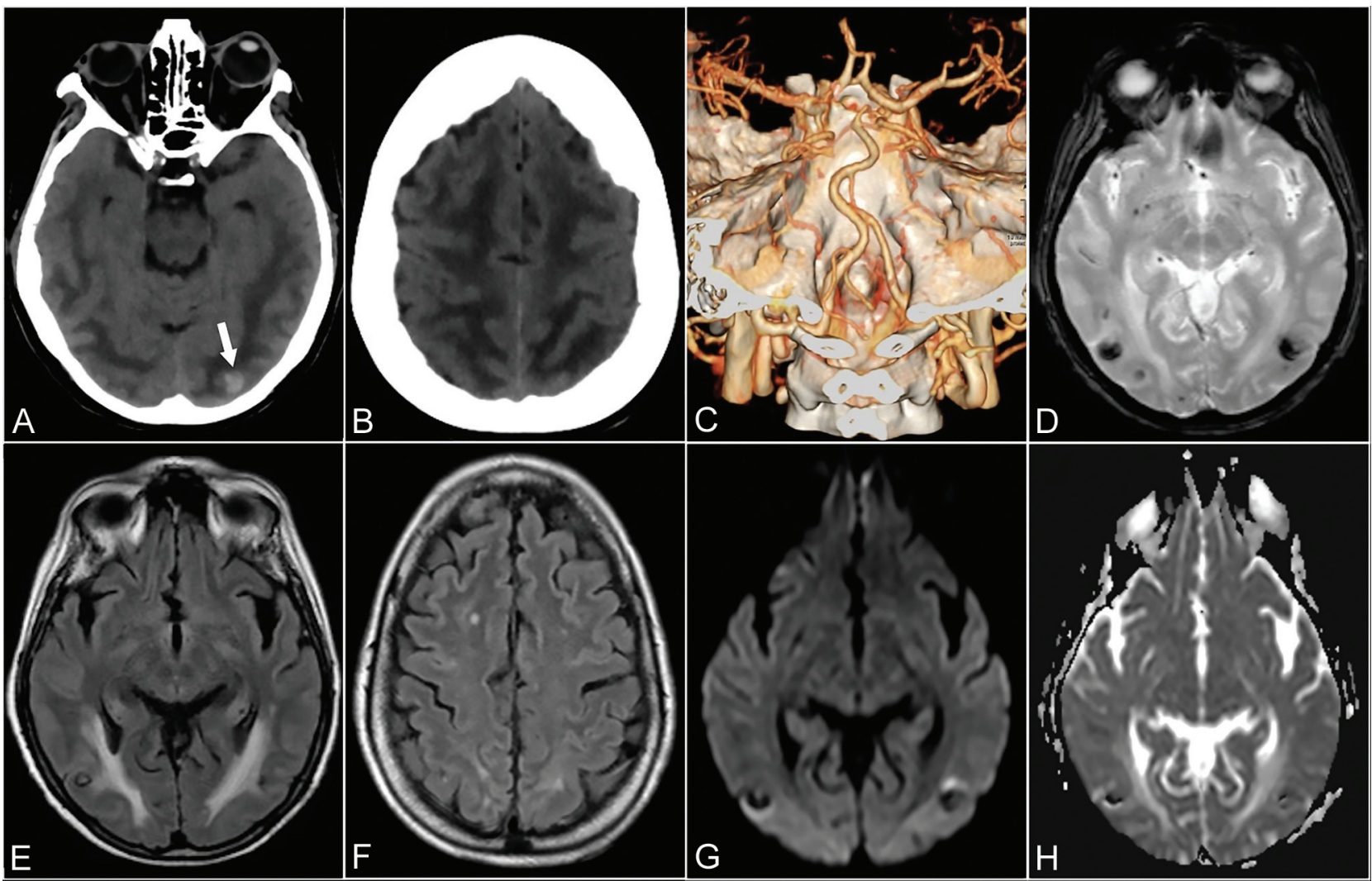

FIG 2. Patient 6. A 64-year-old woman presenting with drowsiness and reduction in visual acuity. Baseline axial CT shows ill-defined, bilateral hemispheric, white matter hypoattenuation, sparing the adjacent cortex, tapering off in the polar aspect of the frontal lobes, consistent with vasogenic edema ( $A$ and $B$ ). A small hyperattenuating lesion is noted in the left occipital lobe, suggestive of focal bleeding (arrow, $A)$. CTA VR reformatted imaging was unremarkable in appearance $(C)$. Three weeks later axial T2* gradient recalled-echo $(D)$, axial T2 FLAIR (E and $F)$, DWI $(G)$, and an ADC map $(H)$ demonstrate a partial resorption of edema and the presence of bilateral focal predominantly hypointense lesions $(E)$ characterized by blooming $(D)$ and signal blackout $(G$ and $H)$ in keeping with focal hemorrhage.

also reported 1 parieto-occipital hemorrhage, 1 case of complicated hemorrhagic PRES, and the hemorrhagic transformation of 2 ischemic strokes. Intracranial hemorrhage in patients with COVID-19 has already been reported. ${ }^{5,19}$ In our series, we also noted 4 hemorrhagic strokes involving the anterior circulation.

One patient in our cohort presented with clinical and imaging features of a severe form of PRES. A recent case report has shown 2 cases of hemorrhagic PRES. ${ }^{20}$ Our patient presented with extensive edema on a baseline CT scan with the presence of hemorrhagic lesions which is a severe and rare manifastation of PRES (Fig 2). ${ }^{21}$ PRES is a multifactorial clinical-radiologic entity characterized by reversible subcortical vasogenic edema. Although not completely elucidated, several pathogenetic theories entailing rapid increase of arterial blood pressure beyond the autoregulatory potential, the release of vasoconstrictors, and endogenous or exogenous stimulants in addition to T-cellderived cytokine release converge to an abnormal activation and consequent disruption of endothelial cell homeostasis. ${ }^{22,23}$ Moreover, infective agents promote polymorphonuclear leukocyte activation and lead to additional release of mediators, resulting in increased vessel permeability, which leads to the development of interstitial edema. ${ }^{23}$ Most interesting, the wellknown frequent association of PRES with posterior circulation involvement has been ascribed to its lack of sympathetic innervation in contrast to the anterior circulation. ${ }^{22,24}$ We ruled out other potential PRES mimickers, such as hypoxic-ischemic encephalopathy, meningoencephalitis, and acute toxic leukoencephalopathy in light of clinical and laboratory data and imaging follow-up. The improvement of pneumonia and laboratory parameters as well as the negative results on subsequent nasopharyngeal swabs paralleled by neurologic symptom resolution may strengthen the hypothesis of SARS-CoV-2 as a primary causative agent. Therefore, endothelial dysfunction, possibly at the capillary level, set off by SARS-CoV-2 infection, may be the etiopathogenesis of PRES.

In our cohort, we found that the posterior circulation was the most common primary site of acute vascular injury. The endothelial disruption related to SARS-CoV-2 could be a common feature acting as a promoting and synergistic agent underlying the preferential involvement of the posterior circulation, presumably due to its intrinsic hemodynamic weakness compared with the anterior circulation. Further studies with larger sample sizes are needed to support our hypothesis.

\section{REFERENCES}

1. WHO Director-General's opening remarks at the media briefing on COVID-19, March 18, 2020. https://www.who.int/dg/speeches/ 
detail/who- director-general-s- opening-remarks-at-the-mediabriefing-on-covid-19-11-march-2020. Accessed May 21, 2020

2. COVID-19 Map: Johns Hopkins Coronavirus Resource Center. https://coronavirus.jhu.edu/map.html. Accessed May 21, 2020

3. Oltre millecento pazienti accolti nelle strutture dedicate all'emergenza Covid-19 dell'ASST Sette Laghi - asstsettelaghi. https://www. asst-settelaghi.it/contenuto-web/-/asset_publisher/shmOK1pliUE0/ content/oltre-millecento-pazienti-accolti-nelle-strutture-dedicateall-emergenza-covid-19-dell-asst-sette-laghi. Accessed May 21, 2020

4. Ahmad I, Rathore FA. Neurological manifestations and complications of COVID-19: a literature review. J Clin Neurosci 2020;77:812 CrossRef Medline

5. Mao L, Jin H, Wang M, et al. Neurologic manifestations of hospitalized patients with coronavirus disease 2019 in Wuhan, China. JAMA Neurol 2020 Apr 10. [Epub ahead of Print] CrossRef Medline

6. Baig AM, Khaleeq A, Ali U, et al. Evidence of the COVID-19 virus targeting the CNS: tissue distribution, host-virus interaction, and proposed neurotropic mechanisms. ACS Chem Neurosci 2020;11: 995-98 CrossRef Medline

7. Li Z, Liu T, Yang N, et al. Neurological manifestations of patients with COVID-19: potential routes of SARS-CoV-2 neuroinvasion from the periphery to the brain. Front Med 2020 May 4. [Epub ahead of Print] CrossRef Medline

8. Mehta P, McAuley DF, Brown M, et al; HLH Across Speciality Collaboration, UK. COVID-19: consider cytokine storm syndromes and immunosuppression. Lancet 2020;395:1033-34 CrossRef Medline

9. Saavedra JM. Brain angiotensin II: new developments, unanswered questions and therapeutic opportunities. Cell Mol Neurobiol 2005; 25:485-512 CrossRef Medline

10. Varga Z, Flammer AJ, Steiger P, et al. Endothelial cell infection and endotheliitis in COVID-19. Lancet 2020;395:1417-18 CrossRef Medline

11. Moriguchi T, Harii N, Goto J, et al. A first case of meningitis/ encephalitis associated with SARS-Coronavirus-2. Int $J$ Infect Dis 2020; 94:55-58 CrossRef

12. Beyrouti R, Adams ME, Benjamin L, et al. Characteristics of ischaemic stroke associated with COVID-19. J Neurol Neurosurg Psychiatry 2020 Apr 30. [Epub ahead of Print] CrossRef Medline
13. Helms J, Kremer S, Merdji H, et al. Neurologic features in severe SARS-CoV-2 infection. $N$ Engl J Med 2020;382:2268-62 CrossRef Medline

14. Giorgianni A, Vinacci G, Agosti E, et al. Neuroradiological features in COVID-19 patients: first evidence in a complex scenario. $J$ Neuroradiol 2020 May 15. [Epub ahead of Print] CrossRef Medline

15. Oxley TJ, Mocco J, Majidi S, et al. Large-vessel stroke as a presenting feature of Covid-19 in the young. $N$ Engl $J$ Med 2020;382:e60 CrossRef

16. Goldberg MF, Goldberg MF. Cerebrovascular disease in COVID19. AJNR Am J Neuroradiol 2020 May 14. [Epub ahead of Print] CrossRef Medline

17. Marietta M, Ageno W, Artoni A, et al. COVID-19 and haemostasis: a position paper from Italian Society on Thrombosis and Haemostasis (SISET). Blood Transfus 2020;18:167-69 CrossRef Medline

18. Bonetti PO, Lerman LO, Lerman A. Endothelial dysfunction: a marker of atherosclerotic risk. Arterioscler Thromb Vasc Biol 2003; 23:168-75 CrossRef Medline

19. Sharifi-Razavi A, Karimi N, Rouhani N. COVID-19 and intracerebral haemorrhage: causative or coincidental? New Microbes New Infect 2020;35:100669 CrossRef Medline

20. Franceschi AM, Ahmed O, Giliberto L. Hemorrhagic posterior reversible encephalopathy syndrome as a manifestation of COVID19 infection AJNR Am J Neuroradiol 2020 May 21. [Epub ahead of Print] CrossRef Medline

21. Hugonnet E, Da Ines D, Boby H, et al. Posterior reversible encephalopathy syndrome (PRES): features on CT and MR imaging. Diagn Interv Imaging 2013;94:45-52 CrossRef Medline

22. Hinduja A. Posterior reversible encephalopathy syndrome: clinical features and outcome. Front Neurol 2020;11:71 CrossRef Medline

23. Fugate JE, Rabinstein AA. Posterior reversible encephalopathy syndrome: clinical and radiological manifestations, pathophysiology, and outstanding questions. Lancet Neurol 2015;14:914-25 CrossRef Medline

24. Gao B, Lyu C, Lerner A, et al. Controversy of posterior reversible encephalopathy syndrome: what have we learnt in the last 20 years? J Neurol Neurosurg Psychiatry 2018;89:14-20 CrossRef Medline 